\title{
Limits of control: The effects of uncontrollability experiences on the efficiency of attentional control
}

\author{
Marcin Bukowski a,*, Dariusz Asanowicz ${ }^{\mathrm{a}}$, Anna Marzecová ${ }^{\mathrm{b}}$, Juan Lupiáñez ${ }^{\mathrm{c}}$ \\ a Institute of Psychology, Jagiellonian University, Kraków, Poland \\ b Institute of Psychology, University of Leipzig, Leipzig, Germany \\ c Departamento de Psicología Experimental, Universidad de Granada, Granada, Spain
}

\section{A R T I C L E I N F O}

Article history:

Received 29 June 2014

Received in revised form 13 November 2014

Accepted 17 November 2014

Available online 5 December 2014

\section{PsycINFO classification:}

2340

2360

Keywords:

Control deprivation

Personal control motivation

Attentional control

Attentional networks

\begin{abstract}
A B S T R A C T
Two experiments were conducted to explore the effects of experiencing uncontrollability on the efficiency of attentional control. The experience of uncontrollability was induced either by unsolvable tasks (Experiment 1 ) or by tasks in which non-contingent feedback was provided (Experiment 2). A version of the Attentional Network Test-Interactions with an additional measure of vigilance (ANTI-V) was used to evaluate the efficiency of the attentional networks (i.e., alerting, orienting, and executive). Results of both experiments revealed a decreased efficiency of executive attention in participants who experienced stable control deprivation but no negative effects in participants who were able to restore their sense of previously deprived control. Additionally, when participants were asked to perform unsolvable tasks and did not receive feedback (Experiment 1), detrimental effects on the orienting network and vigilance were observed. The motivational and cognitive mechanisms underlying the effects of various uncontrollability experiences on conflict resolution and attentional control are discussed.
\end{abstract}

(c) 2014 Elsevier B.V. All rights reserved.

\section{Introduction}

The human natural inclination to perceive oneself as having personal control and a sense of agency has been considered as a basic form of motivation (Bandura, 1977; DeCharms, 1968; Skinner, 1996; Thompson, 1981; White, 1959). The lack or decline of this subjective sense of control may restrict individuals' objective cognitive abilities, efficiency, or resources available to perform successful actions. One strand of research on the effects of control deprivation on cognitive performance has shown that prolonged cognitive engagement in effortful problem solving without success can lead to a state described as cognitive exhaustion (Kofta, 1993; Sedek \& Kofta, 1990). This, in turn, impairs individuals' ability to select and integrate incoming information into meaningful cognitive structures or mental models and diminishes their efficiency in dealing with incongruent and often conflictive pieces of information (in terms of incoming stimuli and the contrast between the expected effects of certain actions and their actual outcomes) (Kofta, 1993; Kofta \& Sedek, 1999; von Hecker \& Sedek, 1999). In addition, preliminary evidence from a dual task paradigm suggests that control deprivation may also affect attentional selection processes

\footnotetext{
* Corresponding author at: Jagiellonian University, Institute of Psychology, ul. Ingardena 6, 30-060 Kraków, Poland.

E-mail address: marcin.bukowski@uj.edu.pl (M. Bukowski).
}

(Kofta \& Sedek, 1998). Therefore, it seems plausible to hypothesize that the function impaired by uncontrollability experiences is attentional control. A different strand of research has suggested that an experience of control deprivation may also have positive effects on individuals' cognitive efficiency. For instance, Wortman and Brehm (1975) suggested that short periods of control deprivation may actually enhance the efficiency of cognitive processes, whereas prolonged experiences of lack of control can lead to cognitive impairment, as predicted by the learned helplessness theory (Seligman, 1975). As hypothesized, short-lasting uncontrollability experiences have been found to lead to an increased tendency to engage in attribution processes, systematic information processing, and more accurate problem-solving strategies (Mikulincer, Kedem, \& Zikha-Segal, 1989; Pittman \& D'Agostino, 1989; Pittman \& Pittman, 1980). In other words, the nature of the uncontrollability effects on cognitive processes seems to depend on time and on the type and intensity of the uncontrollability experiences. Accordingly, it is plausible to consider that an unstable and temporary state of uncontrollability may restore or even enhance the efficiency of attentional control. It should be noted that research on the impact of uncontrollability on attention is scarce and the functioning of attentional control after various uncontrollability experiences has not been directly explored yet. Nevertheless, the literature seems to suggest that subjective experiences of control deprivation may put an additional load on top-down, endogenous attentional control, understood as the ability to deal with incongruent and often conflictive pieces of information (mainly 
between one's goals or the contrast between the expected effects of certain actions and their actual outcomes; Kofta \& Sedek, 1999).

There are several premises supporting the idea of interrelatedness between the experience of personal control and the efficiency of attentional control. One set of premises can be derived from studies on executive attention or executive control (Posner \& DiGirolamo, 2000; Posner \& Petersen, 1990). First, executive attention is supposed to underlie performance monitoring, which helps to achieve an expected level of accuracy or to achieve one's goals by intensifying attentional control when it is necessary to correct inefficient actions or ineffective strategies (e.g., Botvinick, Braver, Barch, Carter, \& Cohen, 2001). Therefore, exposure to unsolvable tasks or incongruent situational demands should directly affect the intensity of conflict monitoring and the efficiency of attentional control. Second, several authors have argued that executive attention underlies or even determines voluntary control and selfcontrol, in terms of cognitive as well as emotional and motivational (e.g. self-regulation) processes (Derryberry, 2002; Posner, 2012; Posner, Rothbart, Sheese, \& Tang, 2007). ${ }^{1}$ Third, it has been shown that personal experiences related to a sense of powerlessness (understood as lack of control in a social context) impair executive functions such as updating and inhibition (Smith, Jostman, Galinsky, \& van Dijk, 2008), decrease the ability to avoid distractors and focus on goalrelevant information (Guinote, 2007), and reduce the efficiency of using spatial orienting cues to improve executive control (Willis, Rodríguez-Bailón, \& Lupiáñez, 2011). These results could therefore lead to analogous predictions of detrimental effects of control deprivation on executive attention. However, this analogy should be taken with caution since, as reported earlier, short-term control deprivation experiences may activate reactance-based motivational mechanisms that can also lead to improved performance (Pittman \& D'Agostino, 1989).

In the present study, two experiments were conducted to explore the relationship between the experience of subjective control and the behavioral efficiency of attentional control. On the one hand, the experience of stable lack of any personal control (i.e., the sense of uncontrollability) may temporarily reduce the efficiency of executive attention, decreasing individuals' ability to distinguish relevant from irrelevant information (i.e., an impaired filtering of signal from noise). On the other hand, if control deprivation indeed impairs executive attention, an experience of subsequent control restoration may act as a positive signal of the possibility to restore lost subjective control by engaging executive attention and thus significantly improve performance. Accordingly, we expected a stable experience of control deprivation to lead to deficits in attentional control (Hypothesis 1); by contrast, we expected a control deprivation experience followed by control restoration to be cognitively stimulating, preventing such deficits and even leading to improved efficiency of attentional control (Hypothesis 2).

Our hypotheses focused primarily on the effects of control deprivation on executive attention, defined in terms of Posner's three attentional networks theory (executive, orienting, and alerting networks) as the ability to resolve conflicts or interferences and regulate ongoing actions, thoughts, and feelings (Petersen \& Posner, 2012; Posner \& Rothbart, 2007). Accordingly, we measured the efficiency of executive attention using a modified version of the Attention Network Test (ANT; Fan et al., 2002; MacLeod et al., 2010). This version provides not only a standard measure of executive control, spatial orienting, and phasic alertness but also a measure of tonic alertness or vigilance, that is, the ability to self-sustain mindful readiness to detect rare and irregularly occurring stimuli (Posner \& Petersen, 1990; Robertson \& O'Connell, 2010). This task was developed by Roca, Castro, LópezRamón, and Lupiáñez (2011) and is called ANTI - Vigilance (ANTI-V).

\footnotetext{
${ }^{1}$ Even though self-control and personal control have different sources and their effects on attention and motivation are also diverse, it seems legitimate to assume that attentional control is required to successfully exert both types of mental control, may it be over the environment or over oneself (see also Baumeister, Heatherton, \& Tice, 1994; Inzlicht \& Schmeichel, 2012; Schmeichel, 2007).
}

We considered that the differentiation between these four relatively independent functions of attention (Fan et al., 2002; MacLeod et al., 2010) would allow us to determine whether the predicted effects of control deprivation are indeed specific to executive attention or reflect a more general impact on a broader range of attentional processes. Moreover, we believed that the choice of this task to measure executive control would enable us to explore whether the predicted effect of experiencing uncontrollability on executive control is modulated by other attentional functions.

\section{Experiment 1}

In Experiment 1, the experience of uncontrollability was activated by using the informational helplessness training procedure developed by Sedek and Kofta (1990), in which uncontrollability is induced by providing a set of unsolvable tasks with no performance feedback. This method has been found to lead to strong performance deterioration effects, induce negative affect, increase subjective feelings of cognitive exhaustion, and impair reasoning processes (Sedek \& Kofta, 1990; von Hecker \& Sedek, 1999). Therefore, we used it as a powerful and well-established manipulation of uncontrollability. The efficiency of the attentional networks was assessed with the ANTI - Vigilance task.

\subsection{Method}

\subsubsection{Participants}

One hundred and five undergraduate students of Jagiellonian University (Kraków, Poland) took part in Experiment 1 in exchange for course credit. Two participants were excluded from the analyses due to a high error rate in the ANTI-V that was close to chance level (50\%) and four participants were excluded based on the results of the manipulation procedure (see the Method section). The remaining sample of 99 participants was composed of 80 female and 19 male participants with a mean age of 20.12 years $(S D=1.46)$. All participants reported normal or corrected-to-normal vision and gave written informed consent before the experiment. Participants were randomly assigned to one of three conditions: control deprivation, control restoration, or baseline.

\subsubsection{Procedure}

Upon arrival, participants were told that the aim of the study was to explore reasoning and attentional skills. After signing the consent form they were seated in front of a computer monitor and asked to perform the first task, which was the uncontrollability manipulation (Informational Helplessness Training; IHT). The manipulation lasted up to 15 min. After completing the IHT task, the attentional network test (ANTI-V) was performed. The task lasted up to $30 \mathrm{~min}$. After the task, participants were asked a set of questions regarding their awareness and the efficiency of the manipulation and debriefed.

2.1.2.1. Informational Helplessness Training (IHT). IHT was used to induce an experience of uncontrollability. It is based on the idea of inducing informational helplessness via a concept-formation task developed by Sedek and Kofta (1990). The IHT task consists of a series of six discrimination problems composed of 12 trials each. In each trial, one figure is presented on the screen at the time. Figures vary on five dimensions: a) size (small or large), b) shape (triangle or circle), c) surface (plain or striped), d) position of a line (at the top or bottom of the figure), and e) size of the letter ' $r$ ' in the middle of the figure (small or large). All participants were informed that all tasks were solvable and participants were told that they could resolve the problem, that is, identify the diagnostic feature of the figures to be discovered (for example, the triangle shape) by using the information (i.e., 'yes' or 'no' accompanying the figure presented on the screen). It was explained that 'yes' means presence (i.e., the figure is a triangle) whereas 'no' means absence of the target feature in the figure (e.g., the figure is a circle). In the 
uncontrollable condition, the sequence of 'yes' and 'no' was arranged in such a way that each possible hypothesis of a problem solution received $50 \%$ of confirmatory and $50 \%$ of disconfirmatory evidence. Hence, it was not possible to solve any of the tasks. In the controllable condition, participants received truthful feedback, that is, 'yes' appeared when the target feature was present in the figure (i.e., when the figure was a triangle in our example) and 'no' appeared when the opposite feature (i.e., a circle) was present. Hence, all the tasks were potentially solvable. After each problem completion, a list of ten features (i.e., possible solutions) was presented to the participants and they were asked to indicate the solution by pressing the corresponding key on the computer keyboard, that is, to point out the target feature. Importantly (and in contrast with the procedure used in Experiment 2), participants were not informed about their success/failure after the completion of consecutive problems in either condition.

In the controllable, baseline condition, all six discrimination problems presented to the participants were solvable; in the control deprivation condition, none of the six problems were solvable; and in the control restoration condition, the first three problems were unsolvable and the second sequence of three problems was solvable. The manipulation was conducted with a between-subjects design.

The experimenter interviewed all participants at the end of the study, asking them how difficult they found the task and whether it affected their feelings of control and efficacy. Two participants in the uncontrollability condition reported that they noticed that the tasks were not solvable. Two participants in the baseline condition (i.e., all solvable tasks) failed to perform any of the tasks correctly (in this condition it was possible to assess the accuracy of the problem-solving activity since there were clear solutions) and reported high difficulty and low sense of control over the task. Therefore, all four participants were excluded from further analyses.

2.1.2.2. Attentional Network Test-Interactions - ANTI- $V$. The efficiency of the attentional networks was measured using the following computer task: a modified version of the Attentional Network Test (ANT, Fan et al., 2002) known as the ANTI - Vigilance or ANTI-V, ${ }^{2}$ developed by Roca et al. (2011; for the ANTI see also Callejas, Lupiáñez, \& Tudela, 2004). In addition to providing the standard ANTI measures of the executive, orienting, and alerting networks, this task directly measures attentional vigilance. Vigilance, as measured with the ANTI-V (which uses a method similar to the SART, cf. Robertson, Manly, Andrade, Baddeley, \& Yiend, 1997) is related to the functioning of the executive network but remains independent of conflict resolution ability (Fan et al., 2007).

An example of a trial and the stimuli used in the ANTI-V are provided in Fig. 1. The target stimulus in the ANTI-V is an arrow pointing either left or right. ${ }^{2}$ In each trial, the target arrow is flanked by four additional arrows pointing either to the same direction (i.e., congruent flankers, $50 \%$ of trials) or to the opposite direction (i.e., incongruent flankers, $50 \%$ of trials). Participants are asked to respond to the direction pointed by the target arrow as quickly and as accurately as possible by pressing one of two specified keys on the computer keyboard (' $c$ ' for left, and ' $m$ ' for right). The incongruent flanker condition involves conflict between two competing reactions, because the incongruent flankers activate the incorrect response, which is opposite to the correct one. Thus, the difference in response times (RTs) between congruent and incongruent conditions indicates the time required to solve the conflict, which is an index of the efficiency of the executive network (Fan et al., 2002). To estimate the efficiency of the orienting network, visual cues $\left({ }^{*}\right)$ are

\footnotetext{
2 Although small cars were used as stimuli in the original task designed by Roca et al. (2011), in our study we used the four-block version of the task with arrows that has been found to be as appropriate to provide similar measures of the attentional networks and vigilance (López-Ramón, Castro, Roca, \& Lupiañez, 2011).
}

introduced in two thirds of the trials. The cue is presented either at the target location, correctly indicating the spatial location of the upcoming target (i.e., valid cue), or at the location opposite to the upcoming target (i.e., invalid cue). The proportion of valid and invalid cues is $50 / 50 \%$. The comparison between individuals' performance under the valid cue condition, in which the target appears in the focus of attention, and the invalid cue condition, in which invalidly directed attention needs to be reoriented to the actual target location, provides an index of the efficiency of orienting (Callejas et al., 2004; Posner, 1980). To estimate the efficiency of alerting, an alerting tone $(2000 \mathrm{~Hz})$ is presented before the visual stimulus in half of the trials (cf. Callejas et al., 2004). The tone signals that the target is about to occur and thereby engages the alerting network. Thus, a comparison between the tone and no tone conditions provides an index of the efficiency of alerting (Callejas et al., 2004; Posner, 2008). To estimate the efficiency of attentional vigilance, a secondary task is introduced. In $25 \%$ of the trials, the target arrow is slightly displaced to the right or to the left. Participants are asked to detect this displacement and press an alternative response key (spacebar), instead of the standard right or left keys (i.e., 'c' or ' $m$ '). As such trials are rare, completion of this secondary task requires high vigilance. A sensitivity index $\left(d^{\prime}\right)$ and a response bias index $(\beta)$ are computed based on the percentage of hits and false alarms. These indices derived from the Signal Detection Theory (Green \& Swets, 1966) are assumed to be reliable indexes of vigilance efficiency (Roca et al., 2011).

The stimuli are displayed at $\sim 0.6^{\circ}$ either above or below the fixation point. The length of the target arrow and the flankers is $\sim 1.7^{\circ}$ of visual angle each. The length of all five arrows is $\sim 10.2^{\circ}$. The distance between the arrows is $\sim 0.44^{\circ}$; in the vigilance trials, however, the target arrow is displaced and appears closer $\left(\sim 0.14^{\circ}\right)$ to the right or left flanker arrow (see Fig. 1). The visual cue (an asterisk) is $\sim 0.85^{\circ}$ long.

Each trial of the task begins with a fixation point displayed at the center of a computer screen for a time interval that varies from 400 to $1600 \mathrm{~ms}$. The fixation point remains displayed during the whole trial. The alerting tone is presented for $100 \mathrm{~ms}$ with $500 \mathrm{~ms}$ of tone-target onset asynchrony, and the orienting cue is presented for $50 \mathrm{~ms}$ with $100 \mathrm{~ms}$ of cue-target onset asynchrony. The target with the flankers is presented for $200 \mathrm{~ms}$. A fixation point like the initial one is displayed immediately after a response is given or after $2000 \mathrm{~ms}$ if the participant does not respond; thus, the total trial time for each trial is always $4100 \mathrm{~ms}$. The whole task is composed of 16 practice trials (with feedback provided after each response) and 256 test trials (without feedback; 192 standard trials and 64 vigilance trials), divided into four blocks of 64 trials each.

\subsubsection{Design and data analysis}

The experiment had a mixed design with condition (control deprivation, restoration, baseline) as a between-participants factor and flanker type (congruent, incongruent), cue (valid, invalid, no cue) and tone (tone, no tone) as within-participant factors.

The conflict effects were analyzed using a $2 \times 3$ ANOVA with Flanker Type (congruent, incongruent) as a within-participants factor, and Control Deprivation (baseline, control deprivation, control restoration) as a between-participants factor. The orienting effects were analyzed by a $2 \times 3$ ANOVA with Cue (valid, invalid) as a within-participant factor, and Condition (baseline, control deprivation, control restoration) as a between-participants factor. No-cue trials were excluded from the orienting effect analyses. The alerting effects were analyzed by a $2 \times 3$ ANOVA with Tone (tone, no tone) as a within-participant factor, and Condition (baseline, control deprivation, control restoration) as a between-participants factor. For the three networks, the dependent variables were response times of correct responses (RTs) and error rates (ERRs). The vigilance trials were excluded from these analyses. If any interaction between Condition and the network effects was significant, separate $2 \times 2$ ANOVAs were conducted to analyze the effects of control deprivation and control restoration. Thus, the Condition factor 


\section{Target conditions}

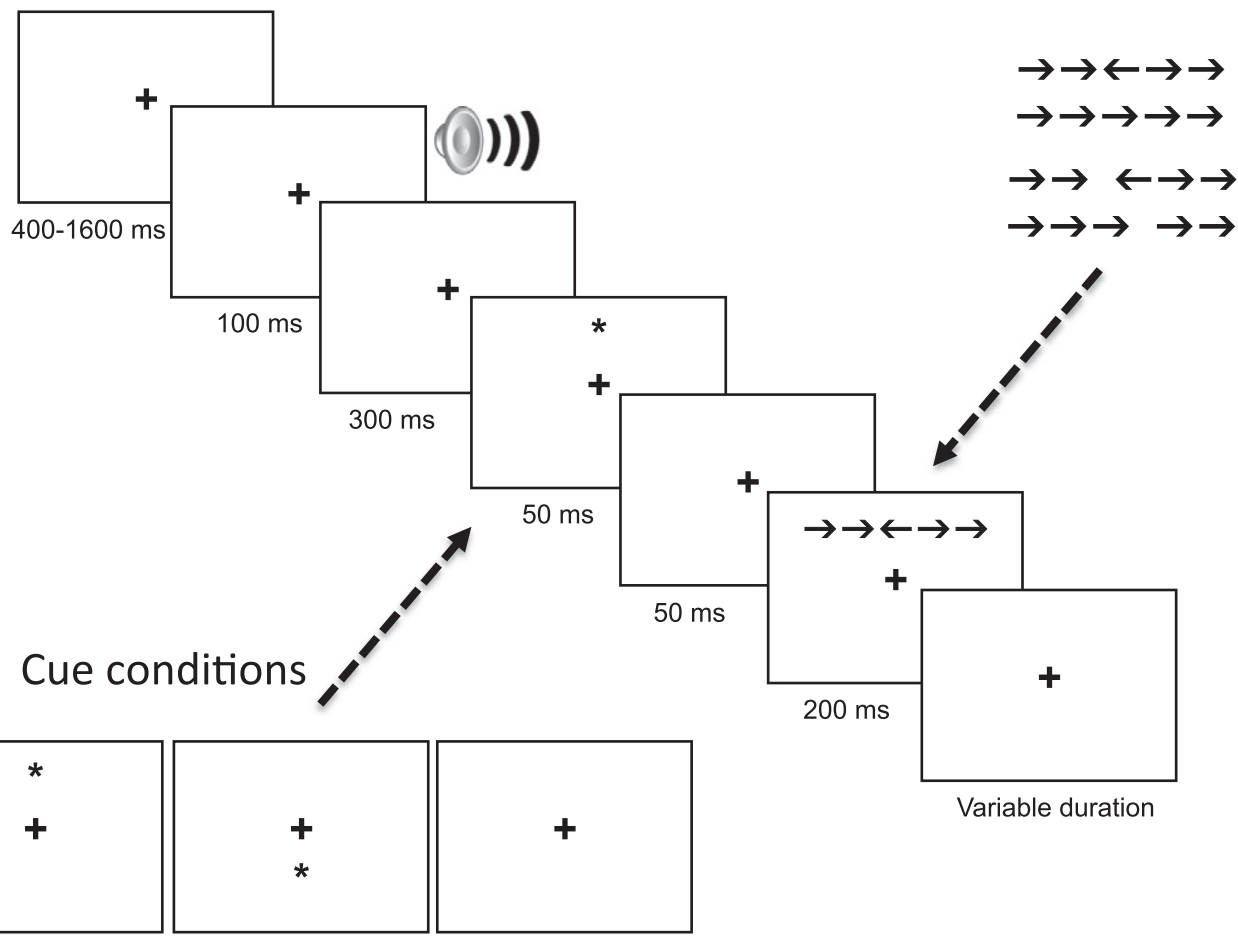

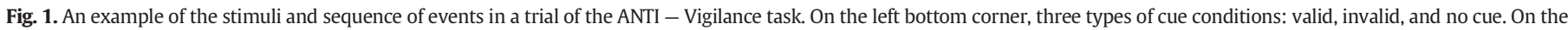

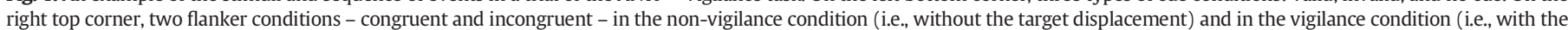
target displacement; see Method for details).

included either baseline and control deprivation conditions or baseline and control restoration conditions. For the vigilance task, the dependent variables were percentages of hits and false alarms and indexes of sensitivity $\left(d^{\prime}\right)$ and response bias $(\beta)$ derived from the Signal Detection Theory (cf. Roca et al., 2011). Simple one-way ANOVAs were performed to analyze possible effects of Condition on vigilance.

\subsection{Results}

\subsubsection{ANTI-V}

2.2.1.1. Overall RT and ERR. Data from all non-vigilance correct trials with RT below 200 ms (i.e., anticipation errors) or three standard deviations

Table 1

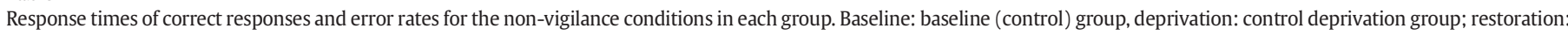
control restoration group; see Method for details.

\begin{tabular}{|c|c|c|c|c|c|c|c|c|c|}
\hline \multirow[t]{3}{*}{ Experiment } & \multirow[t]{3}{*}{ Tone } & \multirow[t]{3}{*}{ Cue } & \multirow[t]{3}{*}{ Flanker type } & \multicolumn{3}{|c|}{ Response times (ms) } & \multicolumn{3}{|c|}{ Error rates (\%) } \\
\hline & & & & Baseline & Deprivation & Restoration & Baseline & Deprivation & Restoration \\
\hline & & & & Mean $(S D)$ & Mean $(S D)$ & Mean $(S D)$ & Mean $(S D)$ & Mean $(S D)$ & Mean $(S D)$ \\
\hline \multirow[t]{12}{*}{$\mathrm{E} 1-\mathrm{IHT}$} & \multirow[t]{6}{*}{ No tone } & \multirow[t]{2}{*}{ No cue } & Congruent & $676(91)$ & $697(90)$ & $664(103)$ & $4.1(6.7)$ & $3.5(4.7)$ & $2.7(6.8)$ \\
\hline & & & Incongruent & $747(115)$ & 787 (103) & $746(746)$ & $7.6(7.4)$ & $12.9(12.4)$ & $7.0(9.2)$ \\
\hline & & \multirow[t]{2}{*}{ Valid cue } & Congruent & $641(109)$ & $656(85)$ & $656(108)$ & $5.3(8.1)$ & $3.3(4.9)$ & $4.7(9.8)$ \\
\hline & & & Incongruent & $721(113)$ & $758(107)$ & 749 (120) & $10.4(11.1)$ & $13.4(13.4)$ & $8.9(10.8)$ \\
\hline & & \multirow[t]{2}{*}{ Invalid cue } & Congruent & $642(97)$ & $683(80)$ & $644(95)$ & $3.1(5.0)$ & $3.7(4.1)$ & $2.8(8.0)$ \\
\hline & & & Incongruent & 748 (99) & $802(95)$ & $756(98)$ & $10.2(9.1)$ & $11.0(9.9)$ & $6.8(8.2)$ \\
\hline & \multirow[t]{6}{*}{ Tone } & \multirow[t]{2}{*}{ No cue } & Congruent & $626(89)$ & $649(77)$ & $638(103)$ & $3.7(6.1)$ & $4.2(5.9)$ & $2.1(3.7)$ \\
\hline & & & Incongruent & $720(119)$ & $769(111)$ & $730(103)$ & $7.4(7.5)$ & $11.6(11.6)$ & $6.1(9.6)$ \\
\hline & & \multirow[t]{2}{*}{ Valid cue } & Congruent & $626(107)$ & $639(78)$ & $627(106)$ & $3.5(6.7)$ & $3.1(4.7)$ & $3.0(5.2)$ \\
\hline & & & Incongruent & $702(108)$ & 744 (107) & 705 (100) & $8.6(10.6)$ & $11.4(12.3)$ & $11.4(12.2)$ \\
\hline & & \multirow[t]{2}{*}{ Invalid cue } & Congruent & $636(88)$ & $654(87)$ & $640(87)$ & $3.7(6.1)$ & $2.4(4.4)$ & $1.5(3.5)$ \\
\hline & & & Incongruent & 758 (99) & 803 (105) & 745 (93) & $8.4(8.2)$ & $13.1(11.4)$ & $6.8(7.1)$ \\
\hline \multirow[t]{12}{*}{$\mathrm{E} 2-\mathrm{BHT}$} & \multirow[t]{6}{*}{ No tone } & \multirow[t]{2}{*}{ No cue } & Congruent & $670(96)$ & $663(93)$ & $684(108)$ & $2.5(3.6)$ & $2.3(5.1)$ & $4.5(7.1)$ \\
\hline & & & Incongruent & 725 (93) & 769 (104) & $741(741)$ & $9.0(5.4)$ & $6.8(8.6)$ & $8.0(8.4)$ \\
\hline & & \multirow{2}{*}{ Valid cue } & Congruent & $643(112)$ & 657 (99) & 644 (107) & $2.5(4.8)$ & $4.5(8.4)$ & $3.8(7.2)$ \\
\hline & & & Incongruent & $724(108)$ & 734 (97) & 717 (107) & $13.3(12.5)$ & $10.5(7.8)$ & $9.0(11.3)$ \\
\hline & & \multirow[t]{2}{*}{ Invalid cue } & Congruent & $656(88)$ & $667(86)$ & $663(96)$ & $1.5(3.3)$ & $3.3(5.4)$ & $4.5(6.6)$ \\
\hline & & & Incongruent & $742(114)$ & 785 (99) & 761 (99) & $7.3(10.5)$ & $10.8(8.6)$ & $7.3(8.8)$ \\
\hline & \multirow[t]{6}{*}{ Tone } & \multirow[t]{2}{*}{ No cue } & Congruent & $631(89)$ & 634 (95) & 655 (98) & $2.3(4.0)$ & $5.5(5.8)$ & $5.3(7.1)$ \\
\hline & & & Incongruent & $721(116)$ & 745 (103) & $723(94)$ & $9.3(11.1)$ & $6.3(7.0)$ & $7.5(8.3)$ \\
\hline & & \multirow[t]{2}{*}{ Valid cue } & Congruent & $624(94)$ & 634 (105) & $623(96)$ & $2.8(4.1)$ & $2.3(3.6)$ & $5.0(10.2)$ \\
\hline & & & Incongruent & 701 (107) & 737 (110) & $736(102)$ & $10(11.7)$ & $7.8(8.9)$ & $11.5(10.8)$ \\
\hline & & \multirow[t]{2}{*}{ Invalid cue } & Congruent & $650(94)$ & $663(97)$ & $662(87)$ & $2.8(4.1)$ & $3.0(4.8)$ & $3.3(5.1)$ \\
\hline & & & Incongruent & 738 (95) & $773(96)$ & 766 (114) & $8.5(9.2)$ & $9.5(8.1)$ & 8.8 (9.7) \\
\hline
\end{tabular}


above the mean (>1366 ms) and all non-vigilance error trials were excluded from the RT analysis ( $2.1 \%$ of all trials in total). The percentage of ERR was calculated only for the non-vigilance trials. Spacebar responses in the non-vigilance trials were counted as vigilance-related errors (i.e., false alarms) and were not counted as errors in the main ANTI task (i.e., the flanker task). Mean RT and ERR in all experimental conditions for each group of participants are presented in Table 1.

After filtering, the overall mean RTs for correct trials were $700 \mathrm{~ms}$ $(S D=90 \mathrm{~ms})$ and overall ERRs were $6 \%(S D=5 \%)$. The effect of the Control Deprivation condition was not significant in the overall RT, $F=1.3$, or the overall ERR, $F=1.8$.

The overall omnibus analyses of the ANTI-V results showed the typical main effects of each variable and the Flanker Type $\times$ Cue, Flanker Type $\times$ Tone, and Tone $\times$ Cue interactions usually observed with the ANTI-V task (e.g., Roca et al., 2011). Thus, for the sake of brevity, only effects related to our hypotheses are reported (statistics for the omnibus analyses are provided in Appendix A).
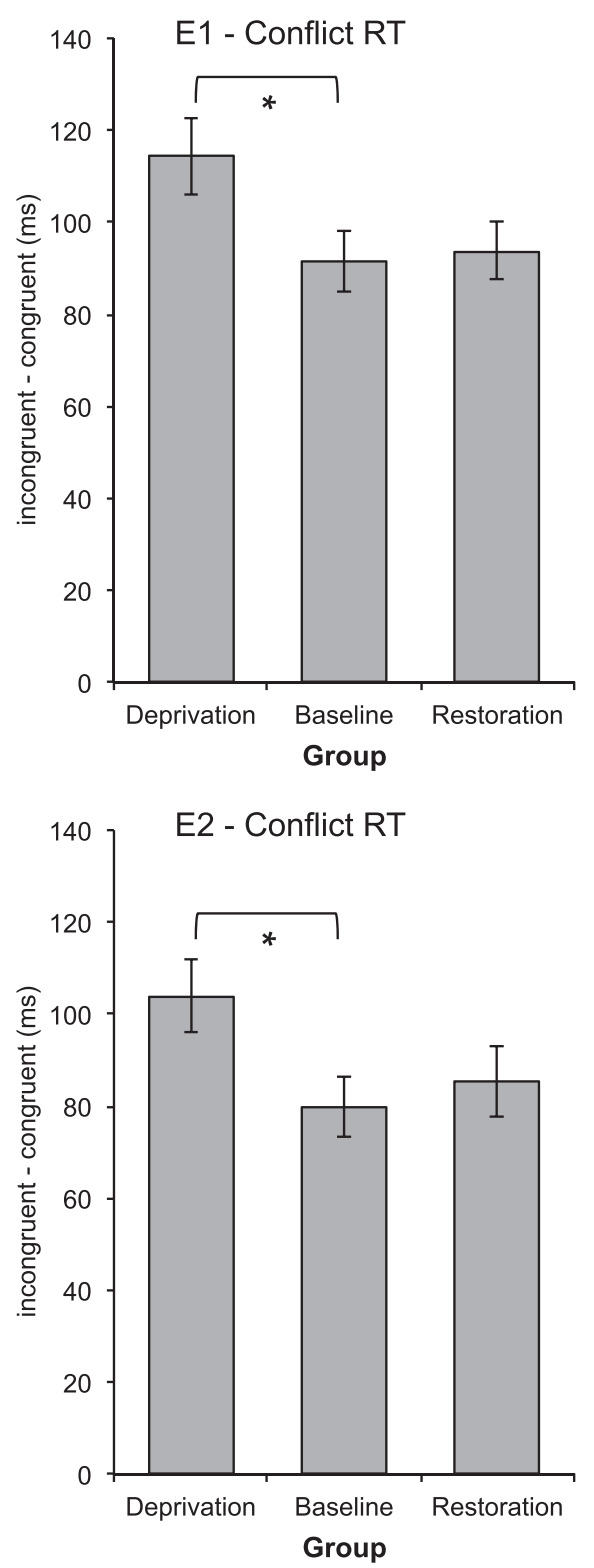

The effect of conflict was $100 \mathrm{~ms}$ in RT, $F(1,98)=594.20, p<.0001$, $\eta_{p}{ }^{2}=.86$, and 6\% in ERR, $F(1,98)=95.38, p<.0001, \eta_{p}{ }^{2}=.50$. Importantly for our hypotheses, Condition modulated the degree of conflict observed, as shown by the significant Condition $\times$ Flanker Type interaction for RT, $F(2,96)=3.20, p=.045, \eta_{p}{ }^{2}=.06$, and for ERR, $F(2,96)=4.24, p=.017, \eta_{p}^{2}=.08$ (see Fig. 2). The conflict effect was significantly larger in the control deprivation condition than in the baseline condition: $23 \mathrm{~ms}$ in RT (Flanker $\times$ Condition: $F(1,64)=4.62$, $p=.035, \eta_{p}{ }^{2}=.07$ ) and $4 \%$ in ERR (Flanker $\times$ Condition: $F(1,64)=$ $5.91, p=.018, \eta_{p}{ }^{2}=.08$ ). The conflict effect was also significantly larger in the control deprivation condition than in the control restoration condition in both RT, $F(1,65)=3.92, p=.05, \eta_{p}{ }^{2}=.06$, and ERR, $F(1$, $65)=5.77, p=.019, \eta_{p}{ }^{2}=.08$. A comparison between the baseline and the control restoration condition did not show any significant differences (all Fs $<1.0$ ). Thus, control deprivation induced higher costs of conflict, but there were no differences in the efficiency of conflict processing between the control restoration and the baseline condition.
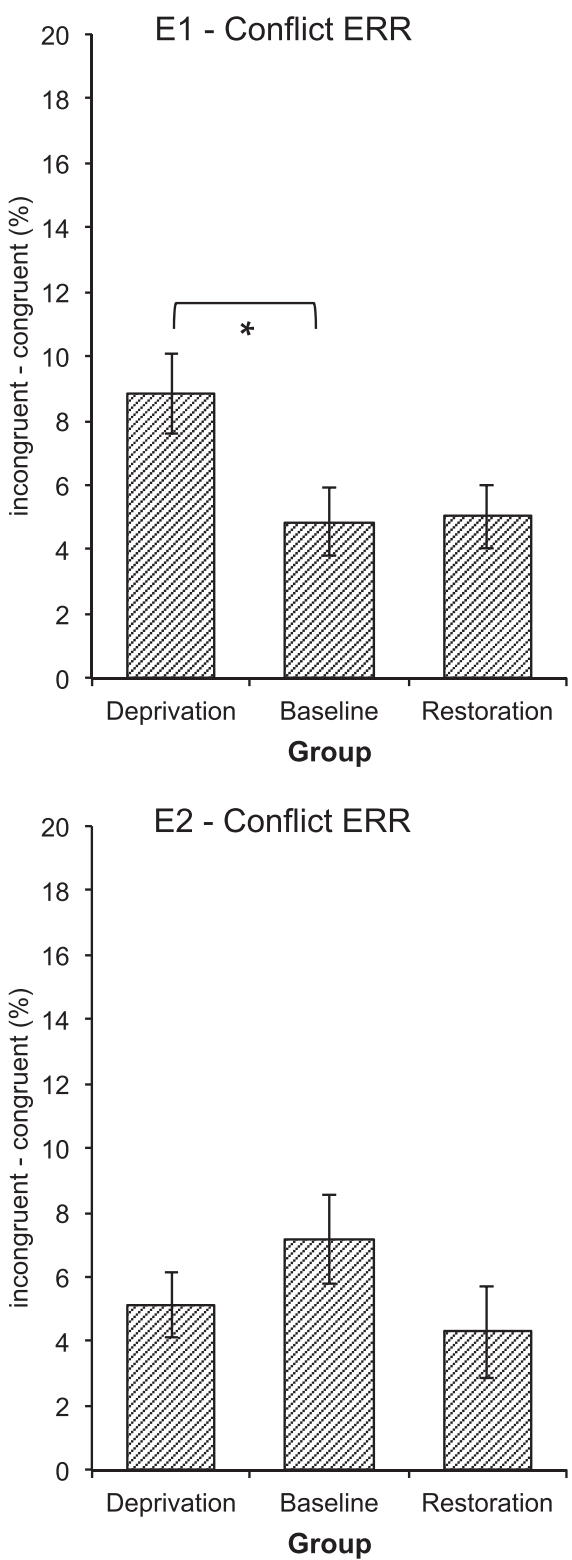

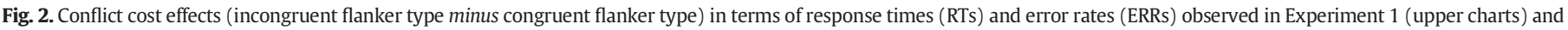

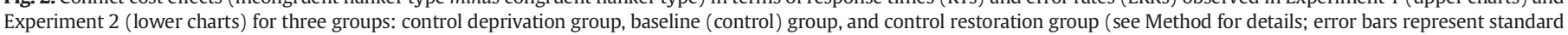
errors). 
We also observed a modulatory effect of Condition on the efficiency of orienting, $F(4,192)=2.35, p=.056, \eta_{p}{ }^{2}=.05$, but not of alertness, $F<1$. As shown by the Tone $\times$ Cue $\times$ Condition interaction, $F(4,192)=$ $3.21, p=.014, \eta_{p}{ }^{2}=.06$, the modulation of orienting by Condition was completely absent in the presence of the tone, $F<1.0$; by contrast, the modulation was significant in the absence of the alerting tone, $F(4$, $192)=4.24, p=.003$. In this case, the control deprivation group showed a larger orienting effect than the other two groups $(F(1$, $96)=3.37, p=.069$, and $F(1,96)=10.43, p=.002$, respectively for the baseline and control restoration groups), which did not differ from each other, $F(1,96)=1.74, p=.178$. It should be noted that alertness has been found to lead to larger orienting effects (Callejas et al., 2004). Thus, uncontrollability led to a larger orienting effect in the conditions when orienting was not benefited by alertness.

In summary, the control restoration group behaved like the baseline group. By contrast, the control deprivation group showed greater interference (i.e., less attentional control) and a larger orienting effect in conditions in which there was no preparation (i.e., in the absence of a warning cue).

2.2.1.2. Vigilance task results. The average percentage of hits was $48 \%(S D=18 \%)$ and the average percentage of false alarms was $4 \%$ $(S D=4 \%)$. The average sensitivity $\left(d^{\prime}\right)$ of the whole sample was 1.8 $(S D=.6)$ and the response bias index $(\beta)$ was $7.9(S D=5.7)$. A significant effect of Condition was observed on the $\beta$ index, $F(2,96)=3.73$, $p=.028, \eta_{p}{ }^{2}=.07$. In the remaining variables the condition effect was not significant ( $F s \leq 1.9$ ). Separate analyses of the effects of control deprivation and control restoration revealed a marginally significant effect of smaller $\beta$ in the control deprivation condition, as compared to the baseline ( 5.9 vs. $8.4, F(1,64)=3.57, p=.063$, $\left.\eta_{p}{ }^{2}=.05\right)$. The effect was not significant in the control restoration manipulation.

\subsection{Discussion}

The results of Experiment 1 showed that an experience of uncontrollability negatively affects the efficiency of executive attention, which is reflected in slower and less accurate responses in the incongruent than in the congruent flanker conditions. At the same time, compared to the baseline condition, no detrimental effect on attentional efficiency was observed in the condition with a short experience of uncontrollability followed by the experience of control restoration. Presumably, sequential restoration of control eliminated the initial control deprivation effects (activated by the first set of unsolvable tasks) so the performance level in this condition was comparable to the baseline condition, which was not exposed to any uncontrollability manipulation. As a result, participants in the control restoration condition dealt with the conflict better than those in the control deprivation condition.

Additionally, the impact of orienting cues on performance was also stronger after stable control deprivation than in the other two conditions, although this effect only occurred in the absence of an alerting tone. This again might indicate an increased tendency to rely on any type of environmental cues that may potentially help to improve performance. Alternatively, this result might suggest that an uncontrollability experience reduced the ability to engage attention and therefore participants were not able to voluntarily overcome the invalid orienting automatically triggered by the cue. The fact that no neutral orienting cues were used in our procedure makes it difficult to distinguish between these two possibilities. In any case, the results of the vigilance task suggest that the tendency to rely on invalid cues and the existence of stronger conflict effects might be related to a less selective response strategy in general. In other words, in the face of uncontrollability participants seemed to be equally vigilant to all types of stimuli (both relevant and irrelevant), paying the cost of decreased efficiency.

\section{Experiment 2}

In this experiment we aimed to replicate the pattern of results observed in Experiment 1 although this time uncontrollability was induced by providing random (i.e., unrelated to performance) feedback. There are reasons to believe that not receiving any feedback on tasks that are unsolvable induces a high level of irreducible uncertainty and may therefore affect attentional control processes more strongly than using a feedback-based procedure (Kofta \& Sedek, 1999). Therefore, the second study was not only a conceptual replication of the first one but was also aimed at resolving a theoretical issue regarding the uniform vs. diverse nature of different uncontrollability experiences. More specifically, the fact of introducing this different type of manipulation allowed us to test whether control deprivation induced by external feedback regarding performance affects executive attention similarly to exposure to unsolvable tasks with no external feedback.

\subsection{Method}

\subsubsection{Participants}

Eighty-three undergraduate students from Jagiellonian University (Kraków, Poland) took part in Experiment 2 in exchange for course credit. Three participants were excluded from the analyses due to a high error rate that was close to chance level (50\%) and five participants were excluded because of their results in the manipulation check after the subjective control manipulation (see the Results section). The remaining sample of 75 participants was composed of 58 female and 17 male participants with a mean age of 20.73 years $(S D=3.61)$. All participants reported normal or corrected-to-normal vision and gave written informed consent before the experiment. Participants were randomly assigned to one of three conditions: control deprivation, control restoration, or baseline (see below).

\subsubsection{Procedure}

In Experiment 2 we used a different uncontrollability manipulation but the same ANTI-V task as in Experiment 1 to measure attentional functions.

Upon arrival, participants were told that the aim of the study was to explore reasoning and attentional skills. After signing the consent form they were seated in front of a computer monitor and asked to perform the first task: the uncontrollability manipulation. The manipulation lasted up to $15 \mathrm{~min}$ and at the end participants were asked some questions on the perceived difficulty of the tasks performed, the evaluation of their performance and their experience of personal control over the outcomes (i.e., manipulation check questions). They also provided answers to twenty-items of the Revised Multiple Affect Adjective Checklist (MAACL-R), which evaluated their transient affective state (Zuckerman \& Lubin, 1985), supplemented by two items that measured perceived level of uncertainty. After completing the uncontrollability experience manipulation, participants performed the ANTI-V (same as in Experiment 1 ). The task lasted up to $30 \mathrm{~min}$. After the task, participants were informed that the experiment was over, thanked, and debriefed.

3.1.2.1. Behavioral Helplessness Training (BHT). Control deprivation was induced by means of the BHT task, applied in a form of a computerized concept-formation task. The task is based on the procedure of inducing short-term uncontrollability experiences developed by Kofta and Sędek (1989), which is an operationalization of the original idea of Seligman and colleagues that the main source of helplessness is a response-outcome non-contingency, that is, lack of perceived coherence between required actions and behavioral outcomes (Hiroto \& Seligman, 1975; Seligman, 1975). It consists of six concept-formation problems. In each problem, participants are presented with a series of ten screens with two stimulus patterns (figures) on each. Each figure contains features from each of the dimensions used in Experiment 1. Pairs of figures are shown sequentially and participants are asked to 
select the figure of the pair that has the feature they believe is the solution. They have to guess at first, but it is explained that by paying attention to the feedback given by the program ('right' or 'wrong') it is possible to determine the diagnostic feature of the figure. In fact, this is the case of all the problems in the control condition. In the helplessness condition, by contrast, feedback was given in a pre-determined random order (the same order for each participant) in all problems, so that each participant was given 50\% 'right' and 50\% 'wrong' feedback on each problem. After each problem completion, a list of ten features (possible solutions) was presented to the participants, who were asked to indicate the solution by pressing the corresponding key on the computer keyboard, that is, to point out the correct feature of the figure. Participants in the control restoration condition were given random feedback in the first three problems and correct feedback in the last three problems. In the baseline condition the feedback provided always accurately informed participants of their actual task performance.

\subsection{Results}

\subsubsection{Manipulation checks}

Since we were interested in manipulating the subjective feeling of control, an important step in the data preparation was selecting the cases in which the manipulation did not work. We decided to exclude results of participants who either reported having a high sense of control over the outcomes in the uncontrollable condition or a low sense of control in the baseline condition. The manipulation check was measured using three questions, which participants answered on a 7-point scale (ranging from 1 - absolutely no control to 7 - full control). Participants in the control deprivation condition whose reported levels of difficulty or control fell over the midpoint of the scale (3) and participants in the baseline or control restoration condition who reported feelings of difficulty or control below the midpoint were excluded from further analyses. In the baseline condition, since the tasks were solvable and feedback was administered according to the performance, we also explored participants' general accuracy level. Participants who failed to perform any of the six tasks correctly or performed only one task correctly and reported having high difficulty were also excluded from further analyses. In short, five participants were excluded.

In order to check for the efficiency of our uncontrollability manipulation, we compared the baseline with the control deprivation condition (perceived accuracy: $M_{\text {baseline }}=5.80, S D_{\text {baseline }}=1.11, M_{\text {c.deprivation }}=$ 2.16, $S D_{\text {c.deprivation }}=1.43, t(48)=10.01, p<.001$; perceived difficulty: $M_{\text {baseline }}=2.84, S D_{\text {baseline }}=1.65, M_{\text {c.deprivation }}=5.52, S D_{\text {c.deprivation }}=$ 1.3, $t(48)=-6.39, p<.001$; perceived control: $M_{\text {baseline }}=5.52$, $S D_{\text {baseline }}=1.05, M_{\text {c.deprivation }}=2.20, S D_{\text {c.deprivation }}=1.3, t(48)=9.99$, $p<.001$ ) and the baseline with the control restoration condition (perceived accuracy: $M_{\text {baseline }}=5.80, S D_{\text {baseline }}=1.11, M_{\text {crestoration }}=3.36$, $S D_{\text {crestoration }}=1.5, t(48)=6.53, p<.001$; perceived difficulty: $M_{\text {baseline }}=$ $2.84, S D_{\text {baseline }}=1.65, M_{\text {crestoration }}=3.92, S D_{\text {crestoration }}=1.47, t(48)=$ $-2.44, p=.018$; perceived control: $M_{\text {baseline }}=5.52, S D_{\text {baseline }}=1.05$, $\left.M_{\text {c.restoration }}=3.36, S D_{\text {crestoration }}=1.15, t(48)=6.95, p<.001\right)$. Results proved the efficiency of the uncontrollability manipulation.

\subsubsection{Emotion measurement}

We also measured participants' temporary emotional state after the manipulation using the Revised Multiple Affect Adjective Check List (MAACL-R) scale (Zuckerman \& Lubin, 1985), which was used to measure states of depression (e.g. sad, depressed; 8 items, $\alpha=$ .92 ), anxiety (e.g. worried, anxious; 4 items, $\alpha=.90$ ), hostility (e.g. angry, hostile; 4 items, $\alpha=.92$ ), and positive emotions (e.g. happy, joyful; 4 items, $\alpha=.92$ ). Additionally, we measured uncertainty using two items (uncertain, disoriented; $\alpha=.89$ ). Participants were asked to indicate on a 7-point scale (ranging from 1 - not at all to 7 - very much) to what extent they felt each of the 20 specific emotional states at that particular time. Two questions measuring uncertainty were added to the scale (e.g. "To what extent do you feel uncertain/disoriented now?").

The analysis comparing emotional effects in the baseline and the control deprivation conditions revealed a significantly higher level of depression $\left(M_{\text {baseline }}=1.48, S D_{\text {baseline }}=1.09, M_{\text {c.deprivation }}=2.43\right.$, $\left.S D_{\text {c.deprivation }}=1.41, t(48)=-2.66, p=.01\right)$, anxiety $\left(M_{\text {baseline }}=\right.$ $1.54, S D_{\text {baseline }}=1.13, M_{\text {c.deprivation }}=2.87, S D_{\text {c.deprivation }}=1.55$, $t(48)=-3.47, p=.001)$ and hostility $\left(M_{\text {baseline }}=1.19, S D_{\text {baseline }}=\right.$ $\left..38, M_{\text {c.deprivation }}=3.04, S D_{\text {c.deprivation }}=1.93, t(48)=-4.69, p<.001\right)$ accompanied by a lower level of positive emotions $\left(M_{\text {baseline }}=4.40\right.$, $S D_{\text {baseline }}=1.42, M_{\text {c.deprivation }}=2.28, S D_{\text {c.deprivation }}=1.16, t(48)=$ $5.77, p<.001)$ in the control-deprived group. Uncertainty scores were also higher in the control deprivation (vs. baseline) condition $\left(M_{\text {baseline }}=1.62, S D_{\text {baseline }}=1.30, M_{\text {c.deprivation }}=3.94, S D_{\text {c.deprivation }}=\right.$ $2.20, t(48)=-4.54, p<.001)$. When the control restoration condition was compared to the baseline, we observed similar but weaker effects of higher depression $\left(M_{\text {baseline }}=1.48, S D_{\text {baseline }}=1.09, M_{\text {crestoration }}=2.21\right.$, $\left.S D_{\text {c.restoration }}=1.14, t(48)=-2.30, p=.026\right)$ and hostility $\left(M_{\text {baseline }}=\right.$ $1.19, S D_{\text {baseline }}=.38, M_{\text {crestoration }}=2.31, S D_{\text {c.restoration }}=1.51, t(48)=$ $-3.60, p=.001)$, but not of anxiety $\left(M_{\text {baseline }}=1.54, S D_{\text {baseline }}=\right.$ $\left.1.13, M_{\text {crestoration }}=2.12, S D_{\text {crestoration }}=1.17, t(48)=-1.78, p=.08\right)$, and lower effects of positive emotions $\left(M_{\text {baseline }}=4.40, S D_{\text {baseline }}=\right.$ $\left.1.42, M_{\text {crestoration }}=3.20, S D_{\text {c.restoration }}=1.47, t(48)=2.93, p=.005\right)$. The uncertainty level was also higher in the control restoration (vs. baseline $)$ condition $\left(M_{\text {baseline }}=1.62, S D_{\text {baseline }}=1.30, M_{\text {c.restoration }}=\right.$ $\left.2.74, S D_{\text {c.restoration }}=1.39, t(48)=-2.95, p=.005\right)$.

\subsubsection{ANTI-V}

3.2.3.1. Overall RT and ERR. Data of all correct non-vigilance trials with RT below $200 \mathrm{~ms}$ or three standard deviations above the mean (>1265 ms) and all non-vigilance error trials were excluded from the RT analysis (2.0\% of all trials in total). ERRs were calculated only for the nonvigilance trials. The spacebar responses in the non-vigilance trials were counted as vigilance-related errors (i.e., false alarms) and were not counted as errors in the main ANTI task (i.e., the flanker task). Mean RT and ERR in all experimental conditions for each group of participants are presented in Table 1.

Overall mean RTs (after the selection) for correct trials were $696 \mathrm{~ms}$ $(S D=90 \mathrm{~ms})$ and overall ERRs were 6\% (SD = 5\%). The main effect of Condition was not significant in the overall RT or the overall ERR $(F s<1.0)$.

As in Experiment 1, the omnibus analyses showed typical main effects of each variable and the Flanker Type $\times$ Cue, Flanker Type $\times$ Tone and Tone $\times$ Cue interactions usually observed with the ANTI-V task (e.g., Roca et al., 2011) (statistics of the omnibus analyses are provided in Appendix A).

The Conflict effect was $90 \mathrm{~ms}$ in RT, $F(1,74)=452.86, p<.0001$, $\eta_{p}{ }^{2}=.86$, and 5\% in ERR, $F(1,74)=55.38, p<.0001, \eta_{p}{ }^{2}=.43$. Crucially, Condition again modulated the degree of conflict in RT measurement, as shown by the Condition $\times$ Flanker Type interaction for RT, $F(2,72)=3.00, p=.055, \eta_{p}{ }^{2}=.08$ (see Fig. 2 ). To test the effects of control deprivation on the efficiency of the executive network, we compared the baseline with the control deprivation condition. The conflict effect was significantly larger in the control deprivation than in the baseline condition, 104 versus $80 \mathrm{~ms}, F(1$, $48)=5.67, p=.021, \eta_{p}^{2}=.11$, with no difference between the conditions in overall RT, $F<1.0$. To test the effects of control restoration, we compared the baseline with the control restoration condition and did not observe any significant difference between these two conditions (all $F s<1$; except the Flanker $\times$ Condition for ERR: $F=2.0$, n.s.). Besides, the RT conflict effect in the control deprivation condition was larger than in the control restoration condition, although this difference was only marginally significant, $F(1,48)=2.93, p=$ $.093, \eta_{p}{ }^{2}=.06$. There were no differences in overall RT between the conditions. 
Moreover, the effects of Condition on the efficiency of executive attention were modulated by the spatial cue factor, as revealed by a significant three-way Cue $\times$ Flanker $\times$ Condition interaction, $F(4,144)=$ 2.68, $p=.034, \eta_{p}^{2}=.07$. An inspection of this interaction showed that the three groups showed similar conflict in valid cue trials, in which orienting helps to reduce interference, all $F s<1.0$. However, the control deprivation group showed a larger conflict than the baseline group in no-cue trials, $F(1,72)=7.80, p=.007$, and a marginally larger conflict in invalid cue trials, $F(1,72)=3.66, p=.059$. The control restoration group did not differ from the control group and also showed less conflict than the control deprivation group, especially in the no-cue condition, $F(1,72)=12.63, p<.001$.

In short, the control deprivation group showed again a larger conflict (i.e., less control) and the control restoration group behaved like the baseline group. This reduced control was more apparent under conditions in which orienting was not able to help in conflict resolution.

3.2.3.2. Vigilance task results. The overall average percentage of hits was $52 \%(S D=19 \%)$; the average percentage of false alarms was $5 \%(S D=$ $4 \%)$. The sensitivity index $\left(d^{\prime}\right)$ was $1.9(S D=.5)$ and the response bias index $(\beta)$ was $6.4(S D=5.6)$. No significant effect of Condition was obtained for any of these variables $(F s<1.0)$.

3.2.3.3. Mediation analyses. We performed a series of mediation analyses in order to test for the indirect effect of the uncontrollability manipulation on the conflict index through negative emotions. None of the effects were significant: a bootstrapping procedure with 5000 samples (see Hayes, 2013) indicated that the indirect effect of the control deprivation condition on the conflict effect through depressive emotions was .08 with a standard error of 1.79 and a $95 \%$ confidence interval $=[-3.74$, 3.83]; the effect of control restoration was also non-significant, with an indirect effect of .04, a standard error of 1.06 and 95\% confidence intervals $=[-1.72,2.53]$. Similarly, no significant indirect effects were found when anxiety or anger subscales were introduced as mediators into the analyses.

\subsection{Discussion}

The results of Experiment 2 showed that a stable experience of control deprivation induced by misleading feedback unrelated to participants' performance can significantly reduce the efficiency of executive attention in conflict resolution. Therefore, response time results replicated the effects obtained in Experiment 1 for the executive network and were in line with our main hypotheses, which predicted that control deprivation experiences would predominantly affect the executive attention. Unlike in Experiment 1, such effects were limited to RT, most probably due to the generally low reliability of ERR measurements, which are often close to a ceiling in tasks like the ANTI-V. However, we did not observe any modulations of vigilance in Experiment 2 either. It seems plausible that the feedback provided in the BHT resulted in weaker and more specific attentional deficits than in the IHT procedure that involved no feedback (which might have activated internal, endogenous feedback). Moreover, the experience of uncontrollability had no negative consequences when it was followed by restoration of personal control. In this case, the efficiency of executive attention was at the same level as in the baseline condition. This suggests that even a short-term experience of performance-congruent feedback, which probably confirms individuals' inner sense of correct performance, seems to allow them to restore their performance to a baseline level. This result replicated the findings of Experiment 1. Therefore, the mechanism of a dynamic experience of control restoration seemed to have a similar impact on executive attention as the manipulation in Experiment 1 , presumably related to a change in a subjective state of perceived self-efficacy.

Additionally, the interaction between orienting and conflict showed that the larger conflict in control-deprived participants (vs. baseline) was observed only when no cue or an invalid cue was presented, which seems to indicate that an experience of uncontrollability may impair the efficiency of attentional control predominantly in the task conditions with increased demands of executive control. This interpretation is consistent with the evidence that valid orienting of attention improves conflict resolution (Asanowicz, Marzecová, Jaśkowski, \& Wolski, 2012; Callejas et al., 2004).

It is also important to note that the uncontrollability manipulation induced higher levels of anxiety, depression, hostility, and uncertainty as compared to the baseline and control restoration conditions. However, those emotional states did not mediate the relation between control deprivation and the efficiency of attentional control. Consistent with this finding, previous research has shown that emotional state manipulations affect the alerting and orienting attentional functions, but not the control function (Garner, Attwood, Baldwin, \& Munafo, 2012; Pacheco-Unguetti, Acosta, Callejas, \& Lupiáñez, 2010). This seems to imply, once more, that an experience of uncontrollability cannot be reduced to specific negative emotions and generates a more complex mental, affective, and motivational state (Kofta, NarkiewiczJodko, \& Kobyliński, 2011; Kofta \& Sedek, 1999; Sedek \& Kofta, 1990).

\section{General discussion}

The results of both experiments showed that induced experiences of uncontrollability (via exposure to unsolvable tasks or feedback that is not contingent with performance) affect the efficiency of executive attention in conflict resolution. This finding confirms our first hypothesis that stable and full uncontrollability experiences have a negative impact on executive attention. Such results are consistent with previous research demonstrating that cognitive exhaustion is a result of control deprivation experiences (Kofta \& Sedek, 1998; Sedek \& Kofta, 1990). Compared to the baseline control group, the manipulation of control restoration did not result in any negative or positive effects on executive attention. This effect may be due to an insufficient level of control deprivation. However, another plausible interpretation of this result might be that the initial control deprivation impaired attentional control, as it did in the control deprivation group, but the following experience of control restoration was sufficient to reduce such negative effects. This interpretation is consistent with the idea that moderate levels of control deprivation can lead to cognitive mobilization effects (Wortman \& Brehm, 1975) or even to improved performance (Mikulincer et al., 1989). However, unlike the studies cited above, we applied a procedure of sequential control restoration and measured the effects on basic processes of attentional control (rather than more complex problemsolving activities). We are not aware of any findings showing the beneficial impact of subjective control experiences on cognitive control. Similar results can be found only in the domain of reward effects on conflict adaptation (van Steenbergen, Band, \& Hommel, 2009).

Additionally, we found that the orienting network can be affected by the control deprivation manipulation. This suggests that uncontrollability may also affect stimulus-driven spatial attention, leading to increased orienting to any type of stimuli that could help to reduce conflict. However, this less selective orienting strategy may eventually lead to an impairment of the goal-driven attentional system. Therefore, participants who experienced uncontrollability might find it more difficult to disengage attention from invalid cues.

Interestingly, our pattern of results resembles that obtained by Pacheco-Unguetti et al. (2010) in participants with high dispositional levels of anxiety. These authors showed that trait anxiety impairs the top-down, goal-driven attentional control system measured in the attentional networks paradigm. However, our results also point to the effect of uncontrollability on the orienting network, which in turn resembles the pattern of results obtained in state-induced anxiety conditions (Garner et al., 2012; Pacheco-Unguetti et al., 2010). This mixed pattern can be explained by referring to the nature of control 
loss experiences, which activate a tendency to seek for solutions to the current problem in the environment but at the same time accumulate experiences of lack of contingency between goals and behavior (attributed to the self). This experience can lead to an overall reduced ability to engage in goal-driven actions, which is reflected in the impoverished functioning of executive attention (Kofta \& Sedek, 1998; Sedek \& Kofta, 1990). The state of experienced stable uncontrollability is likely to be similar to that of dispositional and state anxiety at the same time, since it affects both the orienting and executive networks. Yet, the executive network results were more consistent across two different uncontrollability manipulations, whereas the orienting network effects were smaller and sensitive to the type of manipulation (related vs. unrelated to feedback; see the discussion below). On a more speculative note, prolonged experiences of personal lack of control might also result in adapting chronic anxious attentional biases related to greater sensitivity to threats and negative stimuli.

Our results suggest that transient motivational states related to the sense of personal control may affect the efficiency of executive control. An intriguing question refers to the underlying mechanism that links the motivational and cognitive systems. Looking at the results from a different perspective, one might argue that a deprivation of personal control creates some sort of a state of cognitive conflict between one's goals and the current state that leads to a perceived inability to achieve them. Thus, as any other conflict state, it should trigger an attempt to resolve the conflict, if there are premises suggesting that its resolution may be successful (analogous to the idea that committing an error is supposed to trigger a stronger executive control involvement in the next trial, Botvinick et al., 2001). However, if there seems to be no or little chance for success, as happens in the stable uncontrollability state, any activity of the conflict resolution system should be suspended. In line with this perspective, many researchers claim that emotionally significant signals and control signals are integrated in the prefrontal cortex. In other words, cognitive control mechanisms interact with emotional and motivational ones in the process of guiding our behavior or our actions, and emotions can either impair or enhance cognitive performance depending on how they interact with control functions (e.g., Pessoa, 2009; Vuilleumier, Armony, \& Dolan, 2003).

It has also been suggested that the monitoring system of cognitive control operates through a feedback mechanism (Carter \& Krug, 2012; Gehring \& Willoughby, 2002). Negative feedback produces negative affect, and negative emotions have been shown to impair conflictdriven control (e.g., conflict adaptation, Padmala, Bauer, \& Pessoa, 2011). Moreover, it has been shown that a negative affective state induced by systematic negative feedback that is non-contingent with the actual performance may lead to an impairment of early sensory perception, that is, bottom-up processing in the primary visual cortex, and to narrowing down of attentional focus (see: Rossi \& Pourtois, 2012, 2013). Our findings of poorer performance in the flanker task after an uncontrollability experience are consistent with the perceptual-load-like effects of negative affect on early attentional selection. Negative emotions are strongly related to uncontrollability experiences but it seems that the impaired conflict-resolution efficiency observed in our research cannot be reduced merely to the impact of negative affective states. More research is needed to determine the exact nature of the relationship between motivational and emotional effects of uncontrollability.

On a more basic neural level, the functioning of the dopaminergic system may underlie the relationship between emotions and cognitive control. It is known that the level of dopamine in the brain is sensitive to rewards (Ashby, Isen, \& Turken, 1999) and that dopamine regulates the functioning of the neural network of executive attention (Posner \& Rothbart, 2007). It is therefore possible that an experience of uncontrollability (i.e., lack of reward at the current time but also in the subjectively foreseeable near future) may decrease the efficiency of executive attention by reducing the level of dopamine in the frontal areas of the brain that support executive attention. Interestingly, it has been shown that a reward may reduce conflict effects by enhancing attentional control, probably via changes in dopamine levels (Padmala \& Pessoa, 2011; van Steenbergen et al., 2009). Similarly, our results showed that the negative effects of control deprivation on executive control decrease after an experience of sequential control restoration. Thus, studying the role of dopamine level changes seems an interesting strand of research to follow.

The present results open a relatively new and underexplored topic of the beneficial impact of control restoration on attentional control. So far, the literature on control motivation has shown that reactance processes after moderate amounts of control deprivation may lead to mobilization effects such as enhanced effort involved in a task or improved performance in tasks that require more systematic, controlled processing strategies (Mikulincer et al., 1989; Pittman \& D'Agostino, 1989). Still, to our knowledge, the impact of a sequential control restoration experience on basic processes of attentional control has not been explored yet. In the present research, we found that such experiences may have an immunizing function against the detrimental effects of control deprivation. The mechanism of those effects needs to be further explored, but it seems legitimate to assume that such a dynamic shift between processing modes or mindsets related to a perceived sense of control may positively influence processes of cognitive control.

In addition, our two studies revealed some differences between the existing uncontrollability induction procedures. That is, exposure to unsolvable tasks and lack of feedback affected not only the executive network but also the orienting network and vigilance (Experiment 1); by contrast, the uncontrollability manipulation that involved inconsistent external feedback on participants' performance affected only the executive network (albeit the effect was diminished by presenting the valid cues; Experiment 2). This difference may be related to the fact that the first manipulation was shown to evoke a state of irreducible uncertainty since feedback was missing, and therefore broader attentional effects were observed in comparison to a procedure that involves explicit feedback (Kofta \& Sedek, 1999). Thus, a feedback-based uncontrollability manipulation related to individuals' performance seems to induce stronger selfassessment and self-evaluation. By contrast, lack of feedback and exposure to unsolvable tasks seems to create a state of stronger uncertainty, related to the fact that participants do not know whether the inability to solve the task results from their own lack of competence (i.e., internal factors) or the difficulty of the task (i.e., external factors). This state is likely to affect a broader range of attentional processes, including vigilance. Still, a limitation of this research is that, based on the existing data, the mechanisms that guide the impact of external vs. internal feedback (or lack of feedback) effects on attentional performance cannot be determined.

Finally, it seems important to point out some parallels between the present studies and the current literature on effects of social power (vs. powerlessness) on attentional control. Overall, the pattern of decreased ability to ignore distractors and to engage goal-driven attentional processes remains similar across both lines of research (Guinote, 2007; Smith et al., 2008). Regarding the functioning of attentional networks, as mentioned above, only the feedback-based uncontrollability manipulation had a similar effect on the orienting and executive networks as the powerlessness manipulation, that is, it led to a limited ability to disengage attention from irrelevant cues (Willis et al., 2011). Still, the procedure that contained no feedback also increased participants' tendency to pay more attention to all types of contextual cues, which is in line with some studies that have shown that lack of power may enhance perceptual discrimination in simple cognitive tasks (Weick, Guinote, \& Wilkinson, 2011). Our results show that lack of control, like lack of power, can affect the efficiency of both executive control and spatial orienting. However, we should be cautious in labeling those results as cognitive impairment, since paying attention to a broader range of stimuli and being less selective may also be an adaptive strategy of individuals with a low sense of control who are motivated to search for 
any source of information that might allow them to cope with the task at hand.

To sum up, our research shows that deprivation of subjective control can have an impact on objectively measured, basic attentional processes. In this regard, it is consistent with other studies that have shown that even beliefs in being unlucky may reduce the efficiency of executive functioning (Maltby, Day, Pinto, Hogan, \& Wood, 2013). Such beliefs about one's lack of control may act as an a priori negative feedback or as a state of constant, self-attributed, negative feedback. Finally, we believe that the findings obtained in this research can also be applicable to various social contexts (e.g. unemployment, social exclusion) in which the environment sets the limits for personal control and influences individuals' abilities to engage in more complex problem-solving activities.

\section{Acknowledgments}

This research was supported by a grant (DEC-2011/01/D/HS6/ 00477) financed by the Polish National Science Centre (NCN) awarded to Marcin Bukowski, and also by a grant (PSI2011-22416) awarded by the Spanish Ministerio de Ciencia y Tecnología to Juan Lupiáñez.

\section{Appendix A}

Overall RT and ERR data of the ANTI-V task in Experiments 1 and 2 were analyzed by means of a $2 \times 3 \times 2$ ANOVA with Flanker Type (congruent, incongruent), Cue (valid, invalid, no cue), and Tone (tone, no tone) as within-participant factors.

\section{A.1. Experiment 1}

In the RT analysis, the following effects were significant: the main effects of Flanker Type, $F(1,98)=571.71, p<.0001$, Cue, $F(2,196)=$ $28.84, p<.0001$, and Tone, $F(1,98)=57.53, p<.0001$, as well as the following interactions: Flanker type $\times$ Cue, $F(2,196)=17.38, p<.0001$, Cue $\times$ Tone, $F(2,196)=10.37, p<.0001$, Flanker Type $\times$ Cue $\times$ Tone, $F(2,196)=3.50, p=.033$ (except the Flanker Type $\times$ Tone interaction, $F(1,98)=3.50, p=.064)$. In the ERR analysis, the following main effects were significant: Flanker Type, $F(1,98)=90.67, p<.0001$, and Cue, $F(2,196)=4.28, p=.016$. None of the four interactions were significant.

\section{A.2. Experiment 2}

In the RT analysis, the following effects were significant: the main effects of Flanker Type, $F(1,74)=429.58, p<.0001$, Cue, $F(2,148)=$ $33.84, p<.0001$, and Tone, $F(1,74)=17.28, p<.0001$, as well as all two-way interactions: Flanker Type $\times$ Cue, $F(2,148)=4.78, p=.010$, Cue $\times$ Tone, $F(2,148)=5.00, p=.008$, and Flanker Type $\times$ Tone, $F(1,74)=7.34, p=.008$. The three-way Flanker Type $\times$ Cue $\times$ Tone interaction was not significant, $F(2,196)=1.64, p=.19$. In the ERR analysis, the only significant effects were the main effects of Flanker Type, $F(1,74)=54.76, p<.0001$, and the Flanker Type $\times$ Cue interaction, $F(2,148)=4.14, p=.018$.

\section{References}

Asanowicz, D., Marzecová, A., Jaśkowski, P., \& Wolski, P. (2012). Hemispheric asymmetry in the efficiency of attentional networks. Brain and Cognition, 79(2), 117-128.

Ashby, F.G., Isen, A.M. i, \& Turken, U. (1999). A neuropsychological theory of positive affect and its influence on cognition. Psychological Review, 106, 529-550.

Bandura, A. (1977). Self-efficacy: Toward a unified theory of behavioral change. Psychological Review, 84, 191-215.

Baumeister, R.F., Heatherton, T., \& Tice, D.M. (1994). How and why people fail at self-regulation. San Diego, CA.: Academic Press.

Botvinick, M.M., Braver, T.S., Barch, D.M., Carter, C.S., \& Cohen, J.D. (2001). Conflict monitoring and cognitive control. Psychological Review, 108, 624-652.
Callejas, A., Lupiáñez, J., \& Tudela, P. (2004). The three attentional networks: On their independence and interactions. Brain and Cognition, 54, 225-227.

Carter, C.S., \& Krug, M.K. (2012). Dynamic cognitive control and frontal-cingulate interactions. In M.I. Posner (Ed.), Cognitive neuroscience of attention (pp. 89-98) (2nd ed.). New York, London: Guilford Press.

DeCharms, R. (1968). Personal causation. San Diego, CA: Academic Press.

Derryberry, D. (2002). Attention and voluntary self-control. Self and Identity, 1, 105-111.

Fan, J., McCandliss, B.D., Sommer, T., Raz, A., \& Posner, M.I. (2002). Testing the efficiency and independence of attentional networks. Journal of Cognitive Neuroscience, 14 340-347.

Fan, J., Kolster, R., Ghajar, J., Suh, M., Knight, R.T., Sarkar, R., et al. (2007). Response anticipation and response conflict: An event-related potential and functional magnetic resonance imaging study. The Journal of Neuroscience: The Official Journal of the Society for Neuroscience, 27, 2272-2282.

Garner, M., Attwood, A., Baldwin, D.S., \& Munafo, M.R. (2012). Inhalation of 7.5\% carbon dioxide increases alerting and orienting attention network function. Psychopharmacology, 223(1), 67-73.

Gehring, W.J., \& Willoughby, A.R. (2002). The medial frontal cortex and the rapid processing of monetary gains and losses. Science, 295(5563), 2279-2282.

Green, D.M., \& Swets, J.A. (1968). Signal Detection Theory and Psychophysics. New York: Wiley.

Guinote, A. (2007). Power affects basic cognition: Increased attentional inhibition and flexibility. Journal of Experimental Social Psychology, 43, 685-697.

Hayes, A.F. (2013). Introduction to mediation, moderation, and conditional process analysis: A regression-based approach. New York: The Guilford Press.

Hiroto, D.S., \& Seligman, M.E.P. (1975). Generality of learned helplessness in man. Journal of Personality and Social Psychology, 31, 311-327.

Inzlicht, M., \& Schmeichel, B.J. (2012). What is ego depletion? Toward a mechanistic revision of the resource model of self-control. Perspectives on Psychological Science, 7 450-463.

Kofta, M. (1993). Uncertainty, mental models, and learned helplessness: An anatomy of control loss. In G. Weary, F. Gleicher, \& K. Marsh (Eds.), Control motivation and social cognition (pp. 122-153). New York: Springer.

Kofta, M., Narkiewicz-Jodko, W., \& Kobyliński, P. (2011). Deprywacja kontroli a poznanie i postawy międzygrupowe: Znaczenie deficytów poznawczych i afektywnych [Control deprivation, cognition and intergroup relations: The role of cognitive and emotional deficits]. In M. Kofta, \& M. Bilewicz (Eds.), Wobec obcych: Zagrożenie psychologiczne a stosunki międzygrupoweFacing others: Psychological threat and intergroup relations. Warszawa: Wydawnictwo Naukowe PWN.

Kofta, M., \& Sędek, G. (1989). Repeated failure: A source of helplessness, or a factor irrelevant to its emergence? Journal of Experimental Psychology: General, 118 3-12.

Kofta, M., \& Sedek, G. (1998). Uncontrollability as a source of cognitive exhaustion: Implications for helplessness and depression. In M. Kofta, G. Weary, \& G. Sedek (Eds.), Personal control in action: Cognitive and motivational mechanisms (pp. 391-418). New York: Plenum Press.

Kofta, M., \& Sedek, G. (1999). Uncontrollability as irreducible uncertainty. European Journal of Social Psychology, 29, 577-590.

López-Ramón, Castro, Roca, \& Lupiañez (2011). ANTI-V task: Sample size can be fitted to task assessment requirements? Paper presented at the 17th conference of the ESCOP September 29th-October 2nd.

MacLeod, J.W., Lawrence, M.A., McConnell, M.M., Eskes, G.A., Klein, R.M., \& Shore, D.I. (2010). Appraising the ANT: Psychometric and theoretical considerations of the Attention Network Test. Neuropsychology, 24, 637-651.

Maltby, J., Day, L., Pinto, D.G., Hogan, R.A., \& Wood, A.M. (2013). Beliefs in being unlucky and deficits in executive attention. Consciousness and Cognition, 22, 137-147.

Mikulincer, M., Kedem, P., \& Zikha-Segal, H. (1989). Learned helplessness, reactance and cue utilization. Journal of Research in Personality, 23, 235-247.

Pacheco-Unguetti, A.P., Acosta, A., Callejas, A., \& Lupiáñez, J. (2010). Attention and anxiety: Different attentional functioning under state and trait anxiety. Psychological Science, 21, 298-304

Padmala, S., Bauer, A., \& Pessoa, L. (2011). Negative emotion impairs conflict-driven executive control. Frontiers in Psychology, 4, 192.

Padmala, S., \& Pessoa, L. (2011). Reward reduces conflict by enhancing attentional control and biasing visual cortical processing. Journal of Cognitive Neuroscience, 23(11) 3419-3432.

Pessoa, L. (2009). How do emotion and motivation direct executive control? Trends in Cognitive Sciences, 13, 160-166.

Petersen, S.E., \& Posner, M.I. (2012). The attention system of the human brain: 20 years after. Annual Review of Neuroscience, 35, 73-89.

Pittman, T.S., \& D'Agostino, P.R. (1989). Motivation and cognition: Control deprivation and the nature of subsequent information processing. Journal of Experimental Socia Psychology, 25, 465-480.

Pittman, T.S., \& Pittman, N.L. (1980). Deprivation of control and the attribution process. Journal of Personality and Social Psychology, 39, 377-389.

Posner, M.I. (1980). Orienting of attention. Quarterly Journal of Experimental Psychology, 32(1), 3-25.

Posner, M.I. (2008). Measuring alertness. Annals of the New York Academy of Sciences, $1129,193-199$.

Posner, M.I. (2012). Attention in a social world. New York: Oxford University Press.

Posner, M.I., \& Petersen, S. E. (1990). The attention system of the human brain. Annual Review of Neuroscience, 13, 25-42.

Posner, M. I., \& DiGirolamo, G. J. (2000). Executive attention: Conflict, target detection and cognitive control. In W. R. Parasuraman (rEd.), The attentive brain (pp. 401-423). Cambridge MA: MIT Press. 
Posner, M. I., \& Rothbart, M. K. (2007). Research on attention networks as a model for the integration of psychological science. Annual Review of Psychology, 58, 1-23.

Posner, M.I., Rothbart, M.K., Sheese, B.E., \& Tang, Y. (2007). The anterior cingulate gyrus and the mechanism of self-regulation. Cognitive, Affective, E' Behavioral Neuroscience, 7, 391-395.

Robertson, I.H., Manly, T., Andrade, J., Baddeley, B.T., \& Yiend, J. (1997). 'Oops!': Performance correlates of everyday attentional failures in traumatic brain injured and normal subjects. Neuropsychologia, 35(6), 747-758.

Robertson, I.H., \& O'Connell, R. (2010). Vigilant attention. In A.C. Nobre, \& J.T. Coull (Eds.) Attention and time (pp. 79-88). Oxford University Press.

Roca, J., Castro, C., López-Ramón, M.F., \& Lupiáñez, J. (2011). Measuring vigilance while assessing the functioning of the three attentional networks: The ANTI-Vigilance task. Journal of Neuroscience Methods, 298, 312-324.

Rossi, V., \& Pourtois, G. (2012). State-dependent attention modulation of human primary visual cortex: A high density ERP study. Neurolmage, 60, 2365-2378.

Rossi, V., \& Pourtois, G. (2013). Negative affective state mimics effects of perceptual load on spatial perception. Emotion, 13, 485-496.

Schmeichel, B.J. (2007). Attention control, memory updating, and emotion regulation temporarily reduce the capacity for executive control, 241-255.

Sedek, G., \& Kofta, M. (1990). When cognitive exertion does not yield cognitive gain: Towards an informational explanation of learned helplessness. Journal of Personality and Social Psychology, 58, 729-743.

Seligman, M.E.P. (1975). Helplessness: On depression, development, and death. San Francisco: Freeman.

Skinner, E.A. (1996). A guide to constructs of control. Journal of Personality and Socia Psychology, 71, 549-570.
Smith, P.K., Jostman, N., Galinsky, A.D., \& van Dijk, W.W. (2008). Lacking power impairs executive functions. Psychological Science, 19, 441-447.

Thompson, S.C. (1981). Will it hurt less if I can control it? A complex answer to a simple question. Psychological Bulletin, 90, 89-101.

van Steenbergen, H., Band, G.P.H., \& Hommel, B. (2009). Reward counteracts conflict adaptation: Evidence for a role of affect in executive control. Psychological Science, 20, 1473-1477.

von Hecker, U., \& Sedek G. (1999). Uncontrollability, depression, and the construction of mental models. Journal of Personality and Social Psychology, 77, 833-850.

Vuilleumier, P., Armony, J., \& Dolan, R. (2003). Reciprocal links between emotion and attention. In R.S.J. Frackowiak (Ed.), Human brain functions (pp. 419-444) (2nd ed.). San Diego: Academic Press.

Weick, M., Guinote, A., \& Wilkinson, D. (2011). Lack of power enhances visual perceptual discrimination. Canadian Journal of Experimental Psychology, 65, 208-213.

White, R.W. (1959). Motivation reconsidered: The concept of competence. Psychological Review, 66, 297-333.

Willis, G.B., Rodríguez-Bailón, R., \& Lupiáñez, J. (2011). The boss is paying attention: Power affects the functioning of the attentional networks. Social Cognition, 2, $166-181$.

Wortman, C.B., \& Brehm, J.W. (1975). Responses to uncontrollable outcomes: An integration of reactance theory and the learned helplessness model. In L. Berkowitz (Ed.), Advances in experimental social psychology (pp. 277-336). San Diego, CA: Academic Press.

Zuckerman, M., \& Lubin, B. (1985). Manual for the MAACL-R: The Multiple Affect Adjective Check List-Revised. San Diego, CA: Educational and Industrial Testing Service. 